\title{
Failure of a Fiber Composite Lamina Under Three-Dimensional Stresses
}

\author{
S.J. DeTeresa
}

This article was submitted to

ASME IMECE '99, Nashville, TN, November 14-19, 1999

\section{August 31, 1999}

U.S. Department of Energy

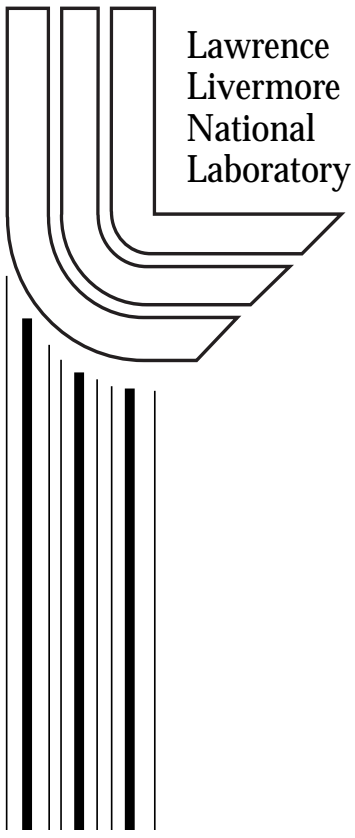




\section{DISCLAIMER}

This document was prepared as an account of work sponsored by an agency of the United States Government. Neither the United States Government nor the University of California nor any of their employees, makes any warranty, express or implied, or assumes any legal liability or responsibility for the accuracy, completeness, or usefulness of any information, apparatus, product, or process disclosed, or represents that its use would not infringe privately owned rights. Reference herein to any specific commercial product, process, or service by trade name, trademark, manufacturer, or otherwise, does not necessarily constitute or imply its endorsement, recommendation, or favoring by the United States Government or the University of California. The views and opinions of authors expressed herein do not necessarily state or reflect those of the United States Government or the University of California, and shall not be used for advertising or product endorsement purposes.

This is a preprint of a paper intended for publication in a journal or proceedings. Since changes may be made before publication, this preprint is made available with the understanding that it will not be cited or reproduced without the permission of the author.

This report has been reproduced

directly from the best available copy.

Available to DOE and DOE contractors from the

Office of Scientific and Technical Information

P.O. Box 62, Oak Ridge, TN 37831

Prices available from (423) 576-8401

http://apollo.osti.gov/bridge/

Available to the public from the

National Technical Information Service

U.S. Department of Commerce

5285 Port Royal Rd.,

Springfield, VA 22161

http://www.ntis.gov/

OR

Lawrence Livermore National Laboratory

Technical Information Department's Digital Library

http://www.llnl.gov/tid/Library.html 


\title{
FAILURE OF A FIBER COMPOSITE LAMINA UNDER THREE-DIMENSIONAL STRESSES
}

\author{
Steven J. DeTeresa \\ University of California \\ Lawrence Livermore National Laboratory \\ Mechanical Engineering Department \\ 7000 East Ave., MS L-342 \\ Livermore, CA 94550 \\ (925) 422-6466, (925) 422-2438 (FAX), deteresa1@IInl.gov
}

\begin{abstract}
The efficient use of thick-section fiber composites requires a proven three-dimensional failure model. Numerous failure criteria have been proposed, but the lack of critical experimental results makes it difficult to assess the accuracy of these models. It is shown that the various predictions for failure of a lamina due to the simple state of uniaxial stress plus superposed hydrostatic pressure are disparate. These differences are sufficient to allow evaluation of failure criteria using data that has the normal scatter found for composite materials. A highpressure test system for fiber composites is described and results for the effects of pressure on the transverse and longitudinal compression strengths of a carbon fiber/epoxy lamina are discussed. Results are compared with a few representative failure models.
\end{abstract}

\section{INTRODUCTION}

An outstanding problem in the analysis of fiber composite materials is the selection of a valid failure model. The problem isn't due to a lack of models - many have been proposed and reviewed in surveys (Rowlands, 1985, Nahas, 1986, Thom, 1998). Rather, the issue is the general acceptance of a single model as the most successful in capturing the response of fiber composites to multiaxial stresses. There is no single fiber composite model that has enjoyed proven success and therefore wide acceptance, as, for example, the von Mises criterion has in the case of isotropic materials.

A popular method of analyzing failure of laminated composite structures is to apply failure criteria to an individual layer of unidirectional material, the lamina, and then determine the effects of damage to the individual lamina on the eventual catastrophic failure of the structure. This approach has the potential benefit of providing failure predictions for any laminated structure using only the properties of the lamina. The recognition of this benefit has led to a great effort in applying lamina-based failure models. However, despite the extensive amount of 
both theoretical and experimental work applied to this problem, there is still uncertainty regarding the effectiveness of this approach even when applied to simple plane stress states. A recent exercise to evaluate twodimensional failure models has been organized by Hinton and Soden (1998). The approach is to compare predictions from several models to data obtained from a consistent set of experiments. While the use of critical experiments is necessary to evaluate failure models, thick-section composites require models and experiments that apply to fully three-dimensional stress states. To this end, we have begun to study the failure of fiber composites under simple triaxial stress states as a method to evaluate failure criteria. This paper summarizes an initial study of the effects of hydrostatic pressure on the uniaxial compression strengths of a fiber composite lamina.

\section{BACKGROUND}

The predictions of the proposed failure models for the simple stress state of pressure plus a uniaxial stress differ significantly and thus provide a means for their evaluation in spite of the normal scatter of test results for fiber composite materials. Much of the previous work to examine the effects of pressure on the strengths of fiber composites has been summarized by Hoppel et al. (1995). The work cited in this review and in a recent study by Zinoviev and Tsvetkov (1998) indicates that strength and failure modes of polymer-based fiber composites exhibit some dependence on pressure. However, the results varied with material, stress state and test method. Many of these studies resorted to nonstandard test specimens in order to perform tests in the confined volume of a pressure cell. Additionally, very few have reported results for a statistically significant number of tests at each pressure. Consequently, it is difficult to use these results to assess the accuracy of the reported effects of pressure on strength and then make the comparison with proposed failure models. In some cases it was observed that the failure mode was changed by the application of hydrostatic pressure (Zinoviev and Tsvetkov, 1998, Parry and Wronski, 1982). For the work reported by Parry and Wronski, (1982) the change in failure mode coincided with a change in the slope of strength (defined here as the stress difference) versus pressure. Since the effect of hydrostatic pressure on the uniaxial strengths of a lamina is a useful method for examining failure models, further results using more standard test methods and more widely studied materials are needed.

\section{EXPERIMENTAL}

All tests were conducted with the carbon fiber/epoxy composite material IM7/8551-7 (Hexcel, Inc. Dublin, CA). This material is useful for failure model evaluation because a full set of lamina elastic constants and strength data are available from several published sources (Jiang and Tennyson, 1989, Kallas and Hahn, 1990, Colvin and Swanson, 1990, Hercules, Inc., 1985). This data set is given in Table 1. Unidirectional 16-ply laminates were autoclave-cured following manufacturer's recommended procedures. All panels were inspected using ultrasonic $\mathrm{C}$-scans and were found to be free from gross defects. The average cured ply thickness was $0.147 \mathrm{~mm}$, which corresponds to a fiber volume fraction of roughly $58 \%$.

Table 1. Elastic constants and strength data for IM7/8551-7.

\begin{tabular}{|c|c|}
\hline Property & Value \\
\hline Longitudinal Young's Modulus, $\mathrm{E}_{11}(\mathrm{GPa})$ : & 162.0 \\
\hline Transverse Young's Modulus, $\mathrm{E}_{22}(\mathrm{GPa})$ : & 8.34 \\
\hline Longitudinal Shear Modulus, $\mathrm{G}_{12}(\mathrm{GPa})$ : & 5.6 \\
\hline Transverse Shear Modulus, $\mathrm{G}_{23}(\mathrm{GPa})$ : & - \\
\hline Longitudinal Poisson's ratio, $v_{12}$ : & 0.30 \\
\hline Transverse Poisson's ratio, $v_{23}$ : & 0.50 \\
\hline Longitudinal Tensile Strength, $\mathrm{X}_{\mathrm{T}}(\mathrm{GPa})$ : & 2.75 \\
\hline Longitudinal Compression Strength, $\mathrm{X}_{\mathrm{C}}(\mathrm{GPa})$ : & 1.60 \\
\hline Transverse Tensile Strength, $\mathrm{Y}_{\mathrm{T}}(\mathrm{MPa})$ : & 75 \\
\hline Transverse Compression Strength, $\mathrm{Y}_{\mathrm{C}}(\mathrm{MPa})$ : & 185 \\
\hline Longitudinal Shear Strength, $\mathrm{S}_{\mathrm{L}}(\mathrm{MPa})$ : & 80 \\
\hline $\mathrm{F}_{12}\left(\mathrm{MPa}^{-2}\right):$ & $8.412 \mathrm{E}-07$ \\
\hline $\mathrm{F}_{23}\left(\mathrm{MPa}^{-2}\right):$ & $\begin{array}{c}-3.914 \mathrm{E}-05,-2.678 \mathrm{E}-05, \\
3.914 \mathrm{E}-05\end{array}$ \\
\hline
\end{tabular}


In order to compare our results for pressure effects with the data collected at ambient conditions, we sought to use standard test methods and specimen configurations. In some cases it was necessary to make modifications to these methods in order to adapt them to testing within a high-pressure cell. However, no method was deemed acceptable until it provided strengths at ambient pressure that were comparable to reported values. A carbon fiber/epoxy composite material was tested for the effects of pressure on both transverse and longitudinal compression strengths. For transverse tests, untabbed rectangular specimens were tested. Both uniform and reduced-width gage section ("dogbone") specimens were examined. The longitudinal strengths were measured using specimens having adhesive-bonded tabs.

Both types of specimens were tested using a two-piece cylindrical fixture that applied both end and shear loading. The design of the fixture was based on studies by Coguill and Adams (1999) and Haberle and Matthews (1994), who showed that combined loading as well as tab compression gave superior results. Set screws were used to apply compression to the tabs via a metal plate. Belleville washers were used under the set screws to maintain a high percentage of this compression when the specimen shrank in thickness under hydrostatic pressure. A precision brass tube was used to maintain the alignment between the two cylindrical fixtures and to prevent bending of the specimen.

The pressure system is comprised of a $1 \mathrm{GPa}$ pressure cell connected at the bottom end to a servo-controlled high-pressure supply system and at the other end to a movable loading piston that contains an internal load cell. The internal load cell is a full-bridge strain gage that measures the differential axial load. The entire system is mounted in a servo-hydraulic test machine that controls the insertion of the piston and compression of the specimen in the pressure cell. Pressure was applied using kerosene as the medium. To test the sensitivity of the composite to kerosene at high pressure, specimens were tested for transverse compression strength at ambient conditions before and after exposure to $345 \mathrm{MPa}$ pressure for 30 minutes. This exposure test was considered severe since the actual time at pressure during a typical test for strength was less than 15 minutes. Results for compression strength and weight change before and after showed that the composite was unaffected by exposure to high-pressure kerosene. Consequently, all tests were conducted with bare specimens.

Compression tests were conducted at 0,172 , and $345 \mathrm{MPa}$ pressure with at least five repeats at each condition.

\section{RESULTS}

\section{Failure Models}

For comparison with data, only a few representative failure models were considered. As additional experimental results are collected in the future, a more extensive comparison will be made. Here results are compared with the maximum stress and strain theories, the Tsai-Wu tensor polynomial (Tsai and Wu, 1971), the Hashin criterion (Hashin, 1980), and the Christensen stress-based criterion (Christensen, 1998). The last two give separate failure criteria for matrix- and for fiber-dominated failures. The Hashin model requires a value for the transverse shear strength, but due to experimental difficulties, this value is normally not measured. Instead, the matrix failure criterion of the Christensen theory can be used to calculate the transverse shear strength from the transverse tensile and compression strengths. When this calculated value of transverse shear strength is used in the matrix compression failure criterion of Hashin's theory, it becomes identical to the Christensen matrix failure criterion.

\section{Failure Due to Hydrostatic Pressure}

Prior to measurement of the effect of pressure on uniaxial strength, the composite was examined for evidence of failure under pure hydrostatic pressure. Although it is commonly accepted that homogeneous, isotropic materials are not susceptible to failure under moderate levels of hydrostatic pressure, yielding of unidirectional organic fiber and metal matrix composites has been observed (Zinoviev and Tsvetkov, 1998, Wakashima and Umekawa, 1976). In both cases, exposure to pressures below $690 \mathrm{MPa}$ resulted in negative plastic strain (shrinkage) transverse to the fiber and positive plastic strain (elongation) in the fiber direction. Due to the mismatch in elastic properties between fiber and matrix, hydrostatic pressure can induce deviatoric stresses in both components and initiate yielding.

A simple square array of circular cross-section fibers was modeled to estimate the magnitude of these stresses. Under hydrostatic pressure it was found that the maximum stress difference occurs in the region where 
fibers are closest to each other. For elastic constituents, the stress difference was found to be $P / 2$, where $P$ is the externally applied hydrostatic pressure. Typical epoxy matrix materials exhibit yield at shear stresses in the range of 50 to $70 \mathrm{MPa}$. Therefore, it is possible that pure pressure in the range of 200-280 ksi could initiate local yielding of the matrix in a unidirectional composite.

Some of the failure models for fiber composites predict failure under pure hydrostatic pressure. Obviously, limit failure models such as the popular maximum stress and strain criteria reach failure conditions when pressure or the strain due to pressure equals the limit in any direction. For most fiber composite lamina, this will occur in the transverse direction first. The tensor polynomial failure models also reach a failure condition under pure pressure. For example, the Tsai-Wu model predicts failure at the critical pressure

$$
P_{c r}=\frac{-\left(F_{1}+2 F_{2}\right)-\sqrt{\left(F_{1}+2 F_{2}\right)^{2}+4\left(F_{11}+2 F_{22}+4 F_{12}+2 F_{23}\right)}}{2\left(F_{11}+2 F_{22}+4 F_{12}+2 F_{23}\right)}
$$

With the values given in Table 1 for the interactive term $F_{23}$, the critical pressure for failure of IM7/8551-7 ranges from about 110 to $250 \mathrm{MPa}$, which is less than the maximum pressure used in the studies conducted here. The previously discussed result for the effects of pressure on the retention of transverse compression strength at ambient conditions indicates that there is no evidence of failure. Measurement of specimen dimensions before and after exposure to $345 \mathrm{MPa}$ pressure showed no change to within a measurement error of $0.01 \%$ strain. Despite the potential for yielding of a lamina under pure pressure and the predictions by some failure models for failure under this loading, the experimental evidence for this particular composite material indicates that its response is elastic under hydrostatic pressure up to $345 \mathrm{MPa}$.

\section{Transverse Compression Strength}

To compare the effect of pressure with failure models, it was decided to define strength as the stress difference for the loading direction rather than the total stress. Thus for the 1-direction aligned with the fiber, uniaxial compression under pressure is given by

$$
\sigma_{11}=P, \sigma_{22}=P+\sigma_{22}^{*}, \sigma_{33}=P
$$

where $\sigma_{22} *$ is the stress difference or transverse strength of the composite. The corresponding case for longitudinal compression is obvious. Here both stresses and pressure are considered positive for tension. With this definition of strength, pressure-independent (Mises-like) behavior is obvious.

The results for testing at the different pressure levels are summarized in Table 2, showing that transverse compression strength increases with pressure. Although there is good agreement between the strengths obtained using the standard uniform-width and dogbone specimens, the scatter is less for the latter. The values for strength at ambient pressure are identical to reported values, indicating that the test method is valid. The uniform-width specimens sometimes failed at the fixture while the dogbone specimens always failed in the reduced width gage section away from the fixture. For this reason, the strength data from the dogbone specimens were considered more accurate. At all three pressures, specimens failed by shear through the thickness. No change in failure mode with pressure was observed. 
Table 2. Effect of pressure on the transverse compression strength of IM7/8551-7.

\begin{tabular}{|c|c|c|}
\hline & \multicolumn{2}{|c|}{ Compression Strength (MPa) } \\
\hline Pressure (MPa) & Straight Specimen & Dogbone Specimen \\
\hline 0 & 173 & 186 \\
& $(4.9)$ & $(3.0)$ \\
\hline 172 & 238 & 237 \\
& $(7.6)$ & $(7.6)$ \\
\hline 345 & 283 & 272 \\
& $(17.2)$ & $(10.3)$ \\
\hline
\end{tabular}

Values in parentheses are standard deviations.

The comparison of these results with the failure criteria is shown in Fig. 1. The Hashin and Christensen models give the correct trend, but overpredict the magnitude of strength increase with pressure. The limit and tensor polynomial failure models predict the opposite trend as well as failure due to pure pressure at values less than those attained in the experiments.

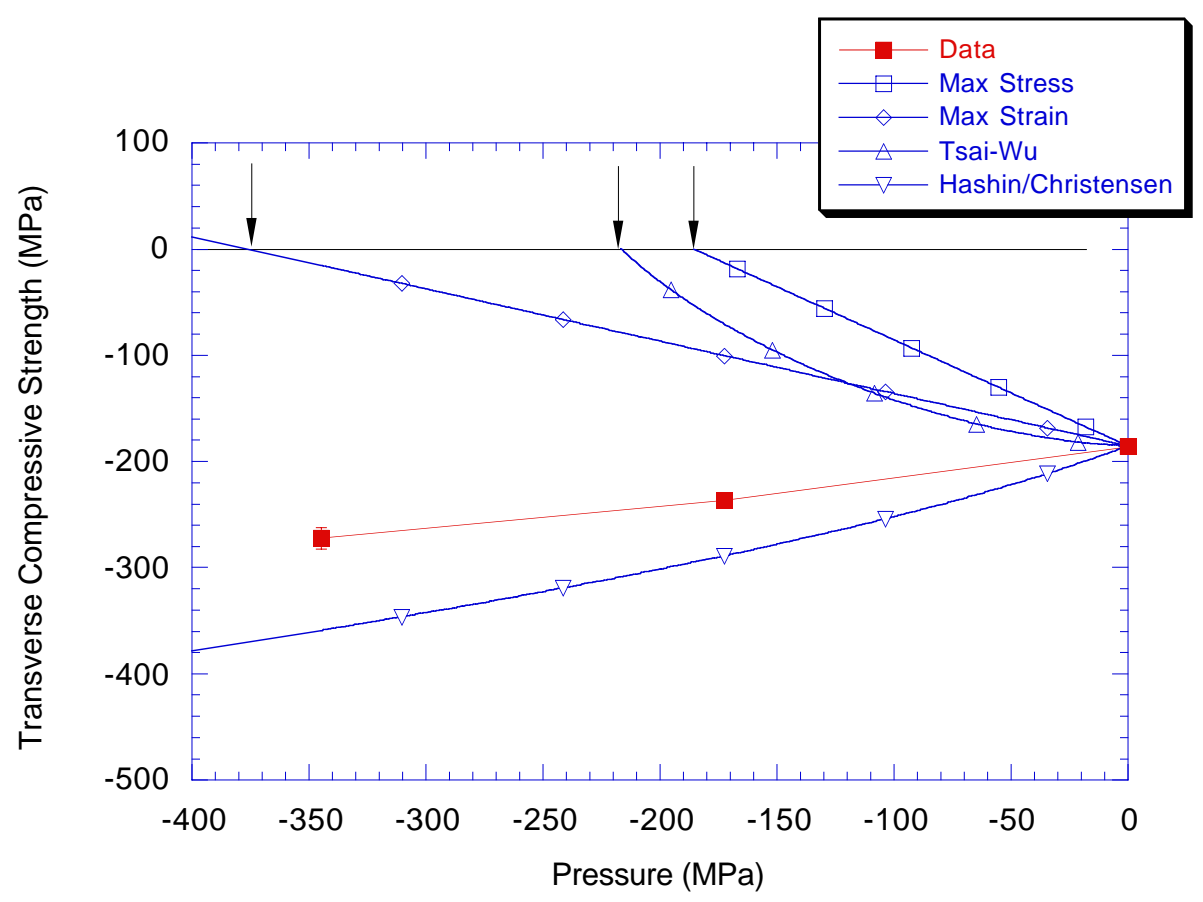

Figure 1. Experimental results and predictions for the effect of pressure on transverse compression strength of IM7/8551-7. 


\section{Longitudinal compression strength}

For compression in the fiber direction, the stress state is given by

$$
\sigma_{11}=P+\sigma_{11}^{*}, \sigma_{22}=P, \sigma_{33}=P
$$

where $\sigma_{11} *$ is the stress difference or longitudinal strength of the composite. The initial strength at ambient pressure was $1.46 \mathrm{GPa}$, which is slightly lower than reported values. This difference could be attributed to fiber volume fraction, which was somewhat lower in the samples used here.

In all cases, failure occurred in the gage section and usually at the end of a tab, which is typical for this type of specimen. No significant change in failure mode was observed at the higher pressures. Pressure resulted in a decrease in strength at a rate that was close to predictions based on the maximum strain and Christensen theories as shown in Fig. 2. The maximum stress and Hashin theories, which are identical for this stress state, predict a much greater loss in strength with pressure. The tensor polynomial theory predicts a significant increase in strength at low pressures followed by a large decrease in strength. It is interesting to compare these results with those obtained by Parry and Wronski (1982). They observed an initial decrease in strength followed by a strength increase at the point the failure mode changed. This reversal in pressure-dependence is predicted only by the Christensen theory, but the predicted effect is much less than found by Parry and Wronski. In fact, these authors state that for their composite the tensile and compression strengths were equivalent. According to the Christensen theory, equivalent strengths yield Mises-like behavior. In other words, strength is independent of pressure.

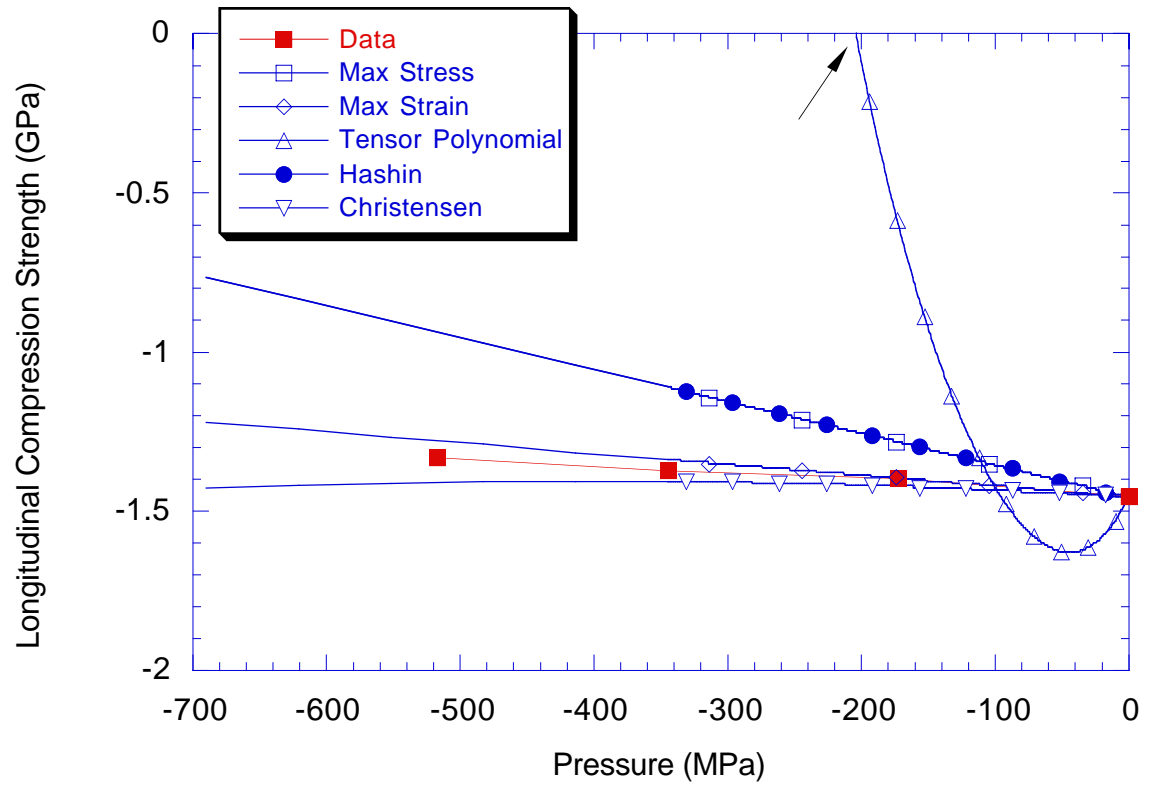

Figure 2. Experimental results and predictions for the effect of pressure on the longitudinal compression strength of IM7/8551-7.

\section{SUMMARY AND CONCLUSIONS}

The effect of pressure on the transverse and longitudinal compression strengths of a carbon fiber/epoxy lamina was measured using newly developed techniques for high-pressure testing of composites. Transverse strength was found to increase and longitudinal strength to decrease with pressure. Unlike previous studies, no change in failure mode due to superposed pressure was observed. The effect of pressure on strength was 
qualitatively predicted by the Hashin and Christensen models for transverse compression failure and by the maximum strain and Christensen models for longitudinal compression failure. These results and those of future studies will be used to critically evaluate proposed three-dimensional failure criteria for thick-section composites.

\section{ACKNOWLEDGEMENTS}

The author gratefully acknowledges the support by the Office of Naval Research under Contract No. N00014-96-F-0422, technical monitor Dr. Y. Rajapakse, and by the Joint DOE/DoD Technology Development Munitions Program. The contributions of Mr. Roberto Sanchez and Mr. Greg Larsen to perform the high-pressure tests and of Mr. Will Andrade and Mr. Jeff Petersen to develop the machining techniques and prepare the specimens are also greatly appreciated.

\section{REFERENCES}

Christensen, R. M., “The numbers of elastic properties and failure parameters for fiber composites,” J. Eng. Mater. Tech. Trans. ASME, 120, 1998, pp. 110-113.

Coguill, S. L. and Adams, D. F., "Use of the Wyoming combined loading compression fixture to test unidirectional composites," Proc. $44^{\text {th }}$ International SAMPE Symp., May, 1999.

Colvin, G. E. and Swanson, S. R., "Mechanical characterization of IM7/8551-7 carbon/epoxy under biaxial stress," J. Eng. Mater. Tech., Trans. ASME, 112(1), 1990, pp. 61-67.

Haberle, J. G. and Matthews, F. L., "An improved technique for compression testing of unidirectional fibrereinforced plastics; development and results," Composites, 25(5), 1994, pp. 358-371.

Hashin, Z., "Failure criteria for unidirectional fiber composites," J. Appl. Mech., 47, 1980, pp. 329-334.

Hercules, Inc., "Magnamite 8551-7 Tough Resin, Graphite Prepreg Tape and Fabric Data Summary," Hercules Aerospace Products Group, Technical Bulletin, November, 1985.

Hinton, M. J. and Soden, P. D., "Predicting failure in composite laminates: the background to the exercise," Comp. Sci. Tech., 58(7), 1998, 1001.

Hoppel, C. P. R., Bogetti, T. A., and Gillespie, J. W. Jr., "Effects of Hydrostatic Pressure on the Mechanical Behavior of Composite Materials," J. Thermoplastic Comp. Mat., 8(4),1995, pp. 375-409.

Jiang, Z. and Tennyson, R. C., J. Comp. Mater., 23(3), 1989, pp. 208-231.

Kallas, M. N. and Hahn, H. T., "A failure criterion for composites under 3-dimensional state of stress," Proc. $35^{\text {th }}$ International SAMPE Symp., April 2-5, 1990, pp. 674-686.

Nahas, M. N., "Survey of failure and post-failure theories of laminated fiber-reinforced composites," $J$. Comp. Tech. Res., 8(4) 1986, pp. 138-153.

Parry, T. V. and Wronski, A. S., "Kinking and compressive failure in uniaxially aligned carbon fibre composite tested under superposed hydrostatic pressure," J. Mater. Sci., 17, 1982, pp. 893-900.

Rowlands, R. E., "Strength (failure) theories and their experimental correlation," in Failure Mechanics of Composites, G. C. Sih and A. M. Skudra, eds., North-Holland, Amsterdam, 1985, pp. 71-125. 869-886.

Thom, H., "A review of the biaxial strength of fibre-reinforced plastics," Comp. Pt A., 29A, 1998 pp.

Tsai, S. W. and Wu, E. M., "A general theory of strength for anisotropic materials," J. Comp. Mater. 5, 1971, p. 58 .

Wakashima, K. and Umekawa, S., "Fiber-composite response to hydrostatic stress," Metall. Trans., 7A, 1976, pp. 1952-1954.

Zinoviev, P. A. and Tsvetkov, S. V., "Mechanical properties of unidirectional organic-fiber-reinforced plastics under hydrostatic pressure," Comp. Sci. Tech. 58, 1998, pp. 31-39. 